CHEN Limin, Wim VAN DOOREN, Lieven VERSCHAFFEL

\title{
The Relationship between Students' Problem Posing and Problem Solving Abilities and Beliefs: A Small-Scale Study with Chinese Elementary School Children
}

\begin{abstract}
The goal of the present study is to investigate the relationship between pupils' problem posing and problem solving abilities, their beliefs about problem posing and problem solving, and their general mathematics abilities, in a Chinese context. Five instruments, i.e., a problem posing test, a problem solving test, a problem posing questionnaire, a problem solving questionnaire, and a standard achievement test, were administered to 69 Chinese fifth-grade pupils to assess these five variables and analyze their mutual relationships. Results revealed strong correlations between pupils' problem posing and problem solving abilities and beliefs, and their general mathematical abilities.
\end{abstract}

Keywords problem posing, problem solving, Chinese pupils, mathematics education

\section{CHEN Limin $(\bowtie)$}

College of Teachers' Professional Development, Shenyang Normal University, Shenyang 110034, China

E-mail: chenlimin_leuven@126.com

\section{Wim VAN DOOREN}

Center for Instructional Psychology and Technology, Katholieke Universiteit Leuven, B-3000 Leuven, Belgium

E-mail: Wim.VanDooren@ppw.kuleuven.be

\section{Lieven VERSCHAFFEL}

Center for Instructional Psychology and Technology, Katholieke Universiteit Leuven, B-3000 Leuven, Belgium

E-mail: Lieven.Verschaffel@ppw.kuleuven.be 


\section{Introduction}

Worldwide recommendations for the reform of school mathematics suggest an important role for problem posing. For example, the Principles and Standards for School Mathematics (National Council of Teachers of Mathematics, 2000) in the United States calls for students to "formulate interesting problems based on a wide variety of situations, both within and outside mathematics" (p. 258). Likewise, the Compulsory Education Mathematics Curriculum Standards (Ministry of Education of The People's Republic of China, 2012) pay attention to students' acquisition of problem posing abilities, emphasizing that students should learn to discover and pose problems from the perspective of mathematics (p. 9). According to these and other documents related to mathematical education reform, the development of problem posing abilities is an important goal of mathematics education, and lies at the heart of mathematical activity. Moreover, the potential value of problem posing in helping students become better problem solvers has been recognized by researchers (Brown \& Walter, 1990, 1993; English, 1997a, 1997b, 1998; Kilpatrick, 1987; Silver, 1994).

Since the late 1980s, there has been growing interest in problem posing among researchers (e.g., Brown \& Walter, 1990, 1993; English, 1997a, 1997b, 1998; Kilpatrick, 1987; Silver, 1994), wherein the topic of the relationship between problem posing and problem solving has received much attention. Several studies have been set up specifically to investigate this issue (e.g., Cai \& Hwang, 2002; Ellerton, 1986; Silver \& Cai, 1996). In those studies students were typically asked to generate one or more problems (of varying levels of difficulty) starting from a given situational description, a picture, or a number sentence. Afterwards, the quality of mathematical problems generated by the students was compared with their problem solving capacities. Results reveal that many students (Cai \& Hwang, 2002; Chen, Van Dooren, Chen, \& Verschaffel, 2005, 2007; Ellerton, 1986; English, 1997a, 1997b, 1998; Silver \& Cai, 1996; Verschaffel, Van Dooren, Chen, \& Stessens, 2009) and even teachers (Chen, Van Dooren, Chen, \& Verschaffel, 2011; Leung \& Silver, 1997; Silver, Mamona-Downs, Leung, \& Kenney, 1996) have trouble posing problems, and that there is a close relationship between students' abilities to pose and solve problems (Cai \& Hwang, 2002; Chen et al., 2005, 2007; Ellerton, 1986; Silver \& Cai, 1996; Verschaffel et al., 2009). However, those studies only explore the relationship between problem posing and problem solving. To date, the relationship between students' abilities to pose and solve problems, their beliefs about problem posing and problem solving, and their general mathematical abilities, has rarely been investigated. One study that sheds some light on this topic was carried out by Nicolaou and Philippou (2007). They examined the relations among efficacy beliefs in problem posing, problem posing abilities, and general mathematical achievement with a sample of 176 Cypriot fifth and sixth 
graders. A four-part questionnaire was used to measure students' abilities in problem posing and their accompanying beliefs regarding efficacy. In the first part, students were asked to read four problem posing tasks and rate their abilities to pose problems based on the four tasks without actually posing any problems. In the second part, the students were asked to select pictures and statements that best expressed their efficacy beliefs about problem posing. In the third part, students were asked to answer 14 five-point Likert items reflecting their efficacy in problem posing, and in the fourth part, the students were asked to pose problems from problem posing tasks similar to those administered to the students in the first part. It was found that students' efficacy beliefs about problem posing measured in the first three parts of the questionnaire were a strong predictor of their performance in problem posing and also their general mathematical skills. However, that study did not involve students' problem solving abilities and beliefs. Moreover, the assessment focused on self-efficacy beliefs about problem posing and did not address other beliefs about problem posing and problem solving (e.g., pleasure in and value attached to these activities). Finally, the Cypriot study and several others have revealed important differences in abilities and beliefs vis-à-vis mathematics between Western and Chinese learners (Cai \& Nie, 2007; Mullis et al., 1997; Mullis, Martin, \& Foy, 2008; Zhang \& Dai, 2004, July).

The relationship between students' problem solving abilities and their beliefs about problem solving has been widely studied. However, research has failed to provide consistent findings regarding the relationship between these two kinds of variables. Some researchers have found that students' beliefs and attitudes regarding mathematics (e.g., their preferences for mathematics or values about mathematics) and students' beliefs about mathematical problem solving (e.g., their self-efficacy or self-concept about mathematical problem solving) were strong predictors of their actual problem solving performance (Hackett \& Betz, 1989; He, 1998; Liu, 2009; Nicolaidou \& Philippou, 2003; Pajares \& Kranzler, 1995). Moreover, some international comparative studies revealed that for most East Asian students, the relationship between their self-efficacy beliefs and their mathematical achievement was not significant. For example, most East Asian students think that they are not doing so well in mathematics despite their high scores on mathematics tests (Leung, 2002). This might be due to their special socio-cultural environment (e.g., very high expectations by teachers and parents of their achievements in mathematics and the central role of high-stake tests for mathematics in the educational system) that interferes in the relationship between their self-efficacy and mathematical achievement (House, 2006; Rao, Moely, \& Sachs, 2000).

So, it remains an interesting question as to whether there are relationships between Chinese students' problem posing and problem solving abilities, their beliefs about problem posing and problem solving, and their general 
mathematical abilities. The main purpose of the present study therefore is to investigate these relationships.

\section{Method}

\section{Participants}

A group of 69 fifth-grade students (average age $=12.2$ years old) participated in the study. They were selected from two classes of a primary school located in the countryside near Shenyang city, China. Their parents' socio-economic status and educational background, and the technical and educational infrastructure of their school were at a relatively low level. Before participating in this study, the students had some occasional experience in problem posing activities since a few problem posing situations appear in the regular textbooks to meet the goal of problem posing described in the Compulsory Education Mathematics Curriculum Standards in China (Ministry of Education of the People's Republic of China, 2012).

\section{Instruments}

Five instruments - a problem posing test (PPT), a problem solving test (PST), a problem posing questionnaire (PPQ), a problem solving questionnaire (PSQ), and a standard achievement test (SAT) — were collectively administered. The first four instruments were administered in two sessions on two successive days with each session lasting for about one hour. In the first session, all students were administered the PPT, and in the next session, they were administered the PST, the PPQ, and the PSQ. The SAT was administered to the students as the final exam of the academic year.

First, a self-made PPT consisting of 12 problem posing items aiming to assess students' problem posing abilities, was administered. The items were selected from different curricular subfields, i.e., arithmetic, geometry, and statistics. In each item students were asked to pose two problems. Hereafter the authors give two examples of problem posing items:

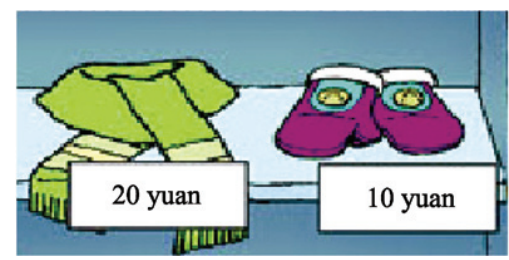


- "Please pose two different word problems derived from the picture";

- "Seven boys and five girls played a mathematics game. Each child was administered 10 problems and the number of correctly solved problems by the group of boys and girls is provided in the following table. Can you think of two different word problems that could be asked starting from this table?"

Boy's group:

\begin{tabular}{ccccccc}
\hline Li Ming & Zhang Hao & Li Fangze & Zhao Peng & Zhou Tong & Qian Dong & Zhou Ming \\
\hline 6 & 4 & 5 & 6 & 7 & 8 & 4 \\
\hline
\end{tabular}

Girl's group:

\begin{tabular}{ccccc}
\hline Li Fang & Liu Ming & Zhang Dong & Chen Ming & Liu Fang \\
\hline 7 & 9 & 10 & 3 & 7 \\
\hline
\end{tabular}

Before the actual PPT, all students were introduced to the test by means of one example of a problem posing item.

Problems posed in the PPT were evaluated along four dimensions, i.e., correctness, complexity, originality, and diversity. Correctness refers to the number of correct mathematical problems posed. To be considered correct, a problem, first, should involve a quantity which is not given in the situation, but which can be computed by means of one or more mathematical operations with the given numbers. Second, the problem should satisfy the requirements of the problem situation (e.g., posing two different word problems was required for each item) or relate to the given problem situation (i.e., using at least one of the knowns, or the goal provided in the situation). Third, the problem should be solvable, i.e., it should provide sufficient information to obtain its goal or its goal should be compatible with the given information. Finally, a correct problem should accord with real world constraints (e.g., a posed problem "A hen lays 10 eggs per day. How many eggs does the hen lay in 13 days?" was considered incorrect because it is realistically impossible for a hen to lay 10 eggs a day). A posed problem was awarded 1 point if it was scored as correct or 0 points if it was scored as wrong. Since two problems were required to be posed in each item (as shown in the above-mentioned example items), each item was awarded a maximum of 2 points, resulting in a total score scale for the dimension of correctness of 0 to $24(2 \times 12)$ points. All the correct problems were also scored in the other three dimensions (i.e., complexity, originality, and diversity) with a higher score reflecting a higher level of problem posing ability. Complexity refers to linguistic complexity (i.e., whether the word problem involved propositions with an assignment, a relational and/or a conditional structure; Silver \& Cai, 1996) and semantic complexity (i.e., combine, change, compare, 
and equalize structures for addition and subtraction word problems; Fuson, 1992) and equal group, multiplicative comparison, rectangular pattern, and Cartesian product for multiplication and division word problems (Verschaffel \& De Corte, 1996) of a correctly posed math problem. More specifically, in line with Silver and Cai (1996), a problem with conditional and/or relational propositions was considered to be more complex than a problem containing only assignment propositions (e.g., the posed problem "The price for 1 scarf is 20 yuan. Xiaoming bought 3 scarves and gave the seller 70 yuan. How much was returned?" was considered more complex than "The price for 1 scarf is 20 yuan, and for 1 pair of gloves is 10 yuan. How much are 2 scarves and 1 pair of gloves?"), and, in line with the same authors, a problem involving a greater variety of semantic relations was considered to be more complex than a problem involving fewer semantic relations (e.g., the posed problem "The price for 1 scarf is 20 yuan, and for 1 pair of gloves is 10 yuan. How much are 2 scarves and 3 pairs of gloves?" received a higher complexity score than "The price for 1 scarf is 20 yuan. How much are 2 scarves?"). Originality refers to the rarity of the mathematical problems being posed ${ }^{1}$. More specifically, a correct problem belonging to a problem type (defined and operationalized in terms of its linguistic, semantic, and mathematical structure) that occurred with a smaller frequency in our whole dataset was considered to be more original than a problem that occurred with a larger frequency. For the dimension of complexity and originality each self-generated problem was awarded from 1 to 5 points, and, so, each item (consisting of two problems, as explained above) was awarded from 2 to 10 points. So the total score for the dimension of complexity and originality was from $24(2 \times 12)$ to $120(10 \times 12)$ points, respectively. The first three criteria can be applied to each individual self-generated problem, whereas the fourth criterion, diversity, addresses the relationship between the two problems that had to be generated by students in a given problem posing item. More specifically, it assesses how much variation there is between the two posed problems in terms of their semantic, linguistic, and mathematical features. For the dimension of diversity (which addressed the relationship between the two problems given for one item) each item was awarded from 1 to 5 points, except for item 4 because this dimension was not applicable to this item $^{2}$, so the total score for the dimension of diversity was from $11(1 \times 11)$ to $55(5 \times 11)$ points. To assess the

\footnotetext{
${ }^{1}$ Since the problems posed will generally reflect the problems that students encountered in their textbooks, and the data coding system might be applied to students with different textbooks and instruction in future studies, the rarity of the mathematical problems was with reference to the dataset rather than to the textbooks.

${ }^{2}$ Since its requirements state "Pose one mathematical problem whose solution would require only addition or subtraction, and one mathematical problem whose solution would require at least one multiplication or division according to the given problem situation," it does not make sense to evaluate the diversity of the posed problems with these specific requirements.
} 
reliability of the scoring method, 10 students were randomly selected and their posed problems were independently scored by two researchers based on the scoring system described above (complemented with a note with more detailed scoring instructions). Inter-rater agreement for the dimension of correctness, complexity, originality, and diversity was $1.00,0.86,0.93$, and 0.93 respectively. Afterwards, the two researchers jointly looked at the posed problems that had yielded different scores and reached an agreement on the final scores for those problems. Finally, one researcher scored all the problems posed by the remaining 59 students based on the assessment criteria and asked for advice if any uncertainties had occurred during this coding process.

Second, researchers developed and administered a PST consisting of 10 problem solving items aimed at assessing students' problem solving abilities. These items were selected from three different curricular subfields, i.e., arithmetics, geometry, and statistics. In each item students were required to answer one or two questions. Hereafter the authors give an example of a problem solving item with two questions and a problem solving item with one question, respectively:

- "On Children's Day, a mother gives her children candies. Xiaoli gets 30 candies, Xiaofang gets twice as many candies as Xiaoli. Xiaoli eats 2 candies per day and Xiaofang eats 4 candies per day.

Question 1: How many candies does mother give to Xiaofang?

Question 2: How many candies should Xiaofang give to Xiaoli to make them have the same number of candies after 5 days?"

- "Mingming recorded how many copies of a new title were sold in his bookshop. In the first week 8 books were sold, in the second week 6 books were sold, and in the third week 10 books were sold.

Question: How many books must Mingming sell in the fourth week so that this title sells an average of 9 a week over the four week period?"

Each answer was scored either as a correct answer, a wrong answer (i.e., an answer using faulty arithmetic operations), a technical error (i.e., an answer with a purely technical mistake in the execution of the arithmetic operation), or no answer. However, because there is not much difference between a completely correct answer and an answer with a purely technical error as far as students' mathematical thinking and understanding of the problem situation is concerned, those with purely technical errors were ultimately considered correct. So items consisting of two questions were awarded 2 points if the two questions were answered correctly, 1 point if only one question was answered correctly, and 0 points when neither of the questions was answered correctly, whereas items consisting of only one question were awarded 2 points if that question was answered correctly, and 0 point in all other cases. This resulted in a maximum 
total score of 20 points for the PST.

Third, PPQ and PSQ tests devised by the researchers that aimed to assess students' beliefs about problem posing and problem solving were administered. The PPQ consisted of twenty 5-point Likert-scale items dealing with students' values about, preference for, perseverance in, and confidence in mathematical problem posing (e.g., "I think pupils can learn a lot from posing mathematical problems" or "I like to pose mathematical problems similar to those in textbooks"). With respect to each item of the PPQ students had to respond by indicating whether they strongly agreed, agreed, were uncertain, disagreed, or strongly disagreed with the statement. The PSQ had a similar content and design to the PPQ, except that the statements were about problem solving instead of problem posing. Each response to the problem posing/solving questionnaire was awarded from 1 to 5 points with a higher score reflecting a more positive belief about problem posing/solving. For a positively formulated item like "In most cases, I can pose/solve mathematical problems successfully in a given situation," the option "strongly disagree" was awarded 1 point, "disagree" 2 points, "uncertain" 3 points, "agree" 4 points, and "strongly agree" 5 points. In case of a negatively formulated item like "I am not very sure whether I can pose mathematical problems in a given situation" or "I don't like solving mathematical problems," the scores were reversed. This resulted in a total score from 20 to 100 points for the PPQ and for the PSQ. Cronbach's (1951) $\alpha$ for the PPQ and PSQ is 0.81 and 0.87 , respectively, which is considered to be a sufficient level of internal consistency (Nunnally \& Bernstein, 1994).

Finally, to assess students' general mathematical knowledge and skills, a SAT developed by Shenyang Municipal Educational Committee was used to assess students' general mathematical knowledge and skills. Questions consisted of five multiple choices, 25 blank fillings, 20 computations, and four word problems related to six curricular subfields (i.e., numbers, addition and subtraction of fractions, solving equations, area of plane figures, word problem solving, and probability). The SAT collected was scored by the teacher responsible for them. The maximum score for the SAT was 100 points. The scale range for the five instruments is listed in Table 1:

Table 1 Scale Range of the PPT, PST, PSQ, and SAT

\begin{tabular}{llcc}
\hline & & Minimum Score & Maximum Score \\
\hline PPT & Correctness & 0 & 24 \\
& Complexity & 24 & 120 \\
& Originality & 24 & 120 \\
& Diversity & 11 & 55 \\
PST & & 0 & 20 \\
PPQ & & 20 & 100 \\
PSQ & & 20 & 100 \\
SAT & & 0 & 100 \\
\hline
\end{tabular}




\section{Results}

First, Table 2 shows students' problem posing performance in the four dimensions (i.e., correctness, complexity, originality, and diversity), indicating that most students were able to pose correct mathematical problems, but that their scores for the other three dimensions (i.e., complexity, originality, and diversity) were rather low.

Table 2 Mean Score (and Standard Deviation) on the PPT for Correctness, Complexity, Originality, and Diversity

\begin{tabular}{lccl}
\hline & Mean & $S D$ & $N$ \\
\hline Correctness & 0.82 & 0.12 & 69 \\
Complexity & 1.93 & 0.43 & 69 \\
Originality & 1.74 & 0.39 & 69 \\
Diversity & 2.96 & 0.60 & 69 \\
\hline
\end{tabular}

Note. The minimum and maximum mean score on the PPT for the dimension of correctness is 0 and 1 point, and for the other three dimensions (i.e., complexity, originality, and diversity) is 1 and 5 points respectively.

Second, compared to the relatively low score for PPT as a whole, the mean score of the PST was $14.52(S D=3.57)$, which indicates that students did relatively well in word problem solving, and the mean score of the SAT was $88.28(S D=12.26)$, indicating high performance in the general mathematical test.

Third, the results for the problem posing questionnaire in Table 3 reveal that students held relatively positive beliefs about problem posing. Most students, for example, thought that problem posing activities could make math lessons more enjoyable and declared that they had a great perseverance in posing problems. However, they had relatively low confidence in their own problem posing abilities and liked to pose problems similar to those in the textbooks. The mean score and standard deviation of the PPQ, as well as the top and bottom two problem posing items according to their mean scores, are displayed in Table 3.

Table 3 Mean Score (and Standard Deviation) of the PPQ and Four Examples of Problem Posing Items.

\begin{tabular}{lrrr}
\hline Problem Posing Items & Mean & $S D$ & $N$ \\
\hline $\begin{array}{l}\text { The math lessons would become more enjoyable if there was more } \\
\text { opportunity for pupils to pose mathematical problems for each other. }\end{array}$ & 4.55 & 0.05 & 69 \\
$\begin{array}{l}\text { I have some difficulties in posing mathematical problems in a given } \\
\text { situation but I manage to do it. }\end{array}$ & 4.26 & 0.76 & 69 \\
$\begin{array}{l}\text { I am the best student in my class in mathematical problem posing. } \\
\text { I like to pose mathematical problems similar to those in the textbooks. }\end{array}$ & 3.04 & 0.96 & 69 \\
Total & $\begin{aligned} 2.22 \\
\text { rol }\end{aligned}$ & 69 \\
\hline
\end{tabular}

Note. The minimum and maximum mean score for each item of the PPQ is 1 point and 5 points respectively. 
Fourth, similar results were found for the PSQ. For example, most students thought problem solving activities could make math lessons more enjoyable and reported great perseverance in solving problems. As for their confidence in their problem solving abilities, it was relatively low. Moreover, they liked to solve problems similar to those in the textbooks. The mean score and standard deviation of the PSQ, as well as the top and bottom two problem solving items according to their mean scores, are displayed in Table 4.

Table 4 Mean Score (and Standard Deviation) of the PSQ and Four Examples of Problem Solving Items.

\begin{tabular}{llll}
\hline Problem Solving Items & Mean & $S D$ & $N$ \\
\hline $\begin{array}{l}\text { The math lessons would become more enjoyable if there was more } \\
\text { opportunities for pupils to solve mathematical problems. }\end{array}$ & 4.49 & 0.78 & 69 \\
$\begin{array}{l}\text { I give up immediately if I can't solve mathematical problems in a } \\
\quad \text { given situation. }\end{array}$ & 4.42 & 0.72 & 69 \\
$\begin{array}{l}\text { I always face great difficulties when asked to solve mathematical } \\
\text { problems despite my efforts. }\end{array}$ & 2.58 & 1.02 & 69 \\
$\begin{array}{l}\text { I like to solve mathematical problems similar with those in } \\
\text { textbooks. }\end{array}$ & 2.04 & 1.16 & 69 \\
$\quad$\begin{tabular}{lll} 
Total \\
\hline
\end{tabular} & 75.57 & 10.83 & 69 \\
\hline
\end{tabular}

Note. The minimum and maximum mean score for each item of the PSQ is 1 point and 5 points respectively.

Fifth, a Pearson Correlation Test revealed that the originality of the posed problems had a significant positive correlation with the dimensions of complexity and diversity ${ }^{3}$. Moreover, the scores for all the four dimensions of the PPT had a significant positive correlation with the performance in the PST and the SAT, except for the correlation between the diversity measure of the PPT and the performance in the SAT. But the originality of the self-generated problems was the only dimension of the PPT that also had a positive significant correlation with the other two instruments, namely the two belief questionnaires. Furthermore, the PPQ had a significant positive correlation with the PSQ, the PST, and the SAT. Finally, the PSQ also had a significant positive correlation with the PST and the SAT. The correlations between these variables are provided in Table 5 .

\footnotetext{
${ }^{3}$ The authors only computed the correlation among complexity, originality, and diversity, except for the dimension of correctness because only correct problems were scored for complexity, originality, and diversity.
} 
Table 5 Correlation between the Four Dimensions (Correctness, Complexity, Originality, and Diversity) of the PPT, PST, PPQ, PSQ, and SAT

\begin{tabular}{lcccccccc}
\hline & Correctness & Complexity & Originality & Diversity & PST & PPQ & PSQ & SAT \\
\hline Correctness & 1.00 & 0.14 & $0.29^{*}$ & 0.15 & $0.39^{* *}$ & 0.22 & 0.23 & $0.37^{* *}$ \\
Complexity & & 1.00 & $0.85^{* *}$ & 0.21 & $0.39^{* *}$ & 0.20 & 0.23 & $0.33^{* *}$ \\
Originality & & & 1.00 & $0.40^{* *}$ & $0.53^{* *}$ & $0.26^{*}$ & $0.28^{*}$ & $0.49^{* *}$ \\
Diversity & & & & 1.00 & $0.38^{* *}$ & 0.17 & 0.13 & 0.21 \\
PST & & & & & 1.00 & $0.30^{*}$ & $0.32^{*}$ & $0.71^{* *}$ \\
PPQ & & & & & & 1.00 & $0.80^{* *}$ & 0.46 \\
PSQ & & & & & & & 1.00 & $0.45^{* *}$ \\
SAT & & & & & & & & 1.00 \\
\hline
\end{tabular}

Note. $N=69 ; *$ Correlation is significant at 0.05 level (two-tailed); $* *$ Correlation is significant at 0.01 level (two-tailed).

\section{Discussion}

The present study investigated a small group of Chinese fifth-grade students' problem posing and problem solving abilities, their problem posing and problem solving beliefs, and their general mathematical abilities, as well as the relationships between all these variables. Results revealed that firstly, these students could pose correct mathematical problems, but that their scores for the complexity, originality, and diversity of these problems were rather low. Secondly, the students did relatively well in the word problem solving test and very well in the general mathematical achievement test, and held relatively positive beliefs about problem posing and problem solving. Thirdly, strong correlations were found between students' abilities to pose mathematical problems, their mathematical problem solving skills, their beliefs about mathematical problem posing and problem solving, and their general mathematical abilities.

The authors end this contribution with a reflection on some restrictions of the present study and some theoretical, methodological, and educational issues that need to be addressed in further research.

First, the present study offered criteria of a well-posed mathematical problem. Specifically, the authors developed a mathematical problem posing test, together with a coding system, to assess students' problem posing abilities. This assessment tool evaluated the problems posed along four dimensions, i.e., correctness, complexity, originality, and diversity. However, some intriguing questions remain, such as: Are these four dimensions sufficient to assess the quintessence of students' problem posing abilities? How should the (meta)cognitive processes underlying students' problem posing performance be 
assessed? Indeed, the four dimensions described in the assessment tool only evaluate the students' performance in the problem posing tasks, but are unable to assess the underlying (meta)cognitive processes. The study of Christou, Mousoulides, Pittalis, Pitta-Pantazi, and Sriraman (2005) contains some useful building blocks towards such a more process-oriented measure. These scholars described students' mathematical problem posing processes in terms of four types of activities, namely, editing, selecting, comprehending and organizing, and translating quantitative information.

Second, the present study explored the relationship between problem posing abilities, problem solving abilities, and general mathematical abilities, and revealed that there were close relationships between these variables. This strengthens the important role of problem posing in mathematics teaching and learning in general. More specifically, these relationships may suggest that problem posing can not only be used as a means to develop students' problem solving abilities, but also as a means to develop students' general mathematical abilities. However, since the present correlational study did not provide any direct evidence of the causal relation between these variables, any claim making should be treated with caution regarding the potential use of word problem posing activities in the development of these variables.

Third, the students who participated in the study were all selected from one particular, small region in China and the sample size was moreover quite small. Both elements evidently jeopardize the external validity or generalizability of the results. So, follow-up studies should involve a larger sample of classes randomly selected from both countryside and inner cities in different regions of China.

Fourth, given that the PPQ and PSQ were administered after the PPT and the PST, students' responses in the two questionnaires might have been affected by the earlier tests. More specifically, some superficial as well as structural characteristics of the tasks presented in the PPT and PST, as well as their difficulty level as experienced by the students, may have directly or indirectly influenced students' beliefs about the attractiveness and value of mathematical problem posing and problem solving tasks and/or their feelings of self-confidence with respect to these tasks. Therefore, in any following studies, it would be better to administer these questionnaires before the tests, or even better, to experimentally control these order effects, in future research. Additionally, results revealed that the PPQ and the PSQ were highly correlated, which might be due to students' similar beliefs about problem posing and problem solving, but may also be (at least partly) due to the similarity in the wording of the two questionnaires. If the latter reason holds true, it might indicate that the authors did not succeed in identifying and measuring two (related but distinct) beliefs. Therefore, in future research this relationship should be further explored, preferably by means of a revised PPQ and PSQ that contain items that are 
textually less similar.

Fifth, compared to the relatively good score on the PST and remarkably good score on the SAT, results revealed that the students in the present study obtained a relatively low score on the PPT as a whole and expressed relatively low confidence in their own problem posing and problem solving abilities. The latter result accords with Leung's (2002) findings. Moreover, as revealed in several previous studies (Hacket \& Betz, 1989; He, 1998; Liu, 2009; Nicolaidou \& Philippou, 2003; Pajares \& Kranzler, 1995), the present study found that there was a close relationship between students' beliefs about problem solving and their problem solving abilities. Therefore, if these results could be confirmed by more large-scale and more representative studies, it would imply that the development of students' problem posing abilities and their beliefs about problem posing and problem solving needs more attention in Chinese mathematics education.

Acknowledgements This research was supported by Grant Education Sciences Planning (JG10DB223) "Experimental research on the development of pupils' problem posing ability in Shenyang City" from the Research Fund of the Shenyang Educational Committee and by Grant GOA 2012/10 "Number sense: Analysis and improvement" from the Research Fund of the Katholieke Universiteit Leuven, Belgium.

\section{References}

Brown. S. I., \& Walter. M. I. (1990). The art of problem posing. Hillsdale, NJ: Lawrence Erlbaum Associates.

Brown, S. I., \& Walter, M. I. (1993). Problem posing in mathematics education. In S. I. Brown \& M. I. Walter (Eds.), Problem posing: Reflections and applications (pp. 16-27). Hillsdale, NJ: Lawrence Erlbaum Associates.

Cai, J., \& Hwang, S. (2002). Generalized and generative thinking in US and Chinese students' mathematical problem solving and problem posing. Journal of Mathematical Behaviour, 21(4), 401-421.

Cai, J., \& Nie, B. (2007). Problem solving in Chinese mathematics education: Research and practice. ZDM: The International Journal on Mathematics Education, 39(5-6), 459-473. doi: $10.1007 / \mathrm{s} 11858-007-0042-3$

Chen, L. M., Van Dooren, W., Chen, Q., \& Verschaffel, L. (2005). The relationship between posing and solving division with remainder problems among Chinese elementary school children. Mediterranean Journal for Research in Mathematics Education, 4(2), 85-109.

Chen, L. M., Van Dooren, W., Chen, Q., \& Verschaffel, L. (2007). The relationship between posing and solving arithmetic word problems among Chinese elementary school children. Journal of the Korea Society of Mathematical Education Series D: Research in Mathematical Education, 11(1), 1-31.

Chen, L. M., Van Dooren, W., Chen, Q., \& Verschaffel, L. (2011). An investigation on Chinese teachers' realistic problem posing and problem solving ability and beliefs. International Journal of Science and Mathematics Education, 9(4), 919-948. 
Christou, C., Mousoulides, N., Pittalis, M., Pitta-Pantazi, D., \& Sriraman, B. (2005). An empirical taxonomy of problem posing processes. ZDM: International Reviews on Mathematical Education, 37(3), 149-158.

Cronbach, L. J. (1951). Coefficient alpha and the internal structure of tests. Psychometrika, 16(3), 297-334.

Ellerton, N. F. (1986). Children's made-up mathematical problems: A new perspective on talented mathematicians. Educational Studies in Mathematics, 17(3), 261-271.

English, L. D. (1997a). The development of fifth-grade children's problem-posing abilities. Educational Studies in Mathematics, 34(3), 183-217. doi: 10.1023/ A:1002963618035

English, L. D. (1997b). Development of seven-grade students' problem posing. In E. Pehkonen (Ed.), Proceedings of the 21st Conference of the International Group for the Psychology of Mathematics Education (Vol. ii, pp. 241-248). Lahti, Finland: University of Helsinki, Lahti Research and Training Centre.

English, L. D. (1998). Children's problem posing within formal and informal contexts. Journal for Research in Mathematics Education, 29(1), 83-106.

Fuson, K. C. (1992). Research on whole number addition and subtraction. In D. A. Grouws (Ed.), Handbook of research on mathematics teaching and learning (pp. 243-275). New York, NY: Macmillan.

Hackett, G., \& Betz, N. E. (1989). An exploration of the mathematics self-efficacy/ mathematics performance correspondence. Journal for Research in Mathematics Education, 20(3), 261-273.

He, X. Y. (1998). 小学生数学自我效能, 自我概念与数学成绩关系的研究 [Research on the relationship between elementary school pupils' math self-efficacy, self-concept and their mathematics academic achievement]. 心理发展与教育 [Psychological Development and Education], (1), 45-48.

House, J. D. (2006). Mathematics beliefs and achievement of elementary school students in Japan and the United States: Results from the third international mathematics and science study. The Journal of Genetic Psychology, 167(1), 31-45.

Kilpatrick, J. (1987). Problem formulating: Where do good problems come from? In A. H. Schoenfeld (Ed.), Cognitive science and mathematics education (pp. 123-147). Hillsdale, NJ: Lawrence Erlbaum Associates.

Leung, F. K. S. (2002). Behind the high achievement of East Asian students. Educational Research and Evaluation: An International Journal on Theory and Practice, 8(1), 87-108. doi: 10.1076/edre.8.1.87.6920

Leung, S. S., \& Silver, E. A. (1997). The role of task format, mathematics knowledge, and creative thinking on the arithmetic problem posing of prospective elementary school teachers. Mathematics Education Research Journal, 9(1), 5-24.

Liu, Z. (2009). 大学生数学自我效能, 自我概念与数学学业成绩关系的研究 [Research on the relationship between college students' math self-efficacy and self-concept and their mathematics academic achievement]. 数学教育学报 [Journal of Mathematics Education], 18(6), 37-41.

Ministry of Education of the People's Republic of China. (2012). 义务教育数学课程标准 [Compulsory education mathematics curriculum standards]. 北京, 中国: 北京师范大学 出版社 [Beijing, China: Beijing Normal University Publishing House].

Mullis, I. V. S., Martin, M. O., Beaton, A., Gonzalez, E., Kelly, D., \& Smith, T. A. (1997). Mathematics achievement in the primary school years: IEA's third international mathematics and science study (TIMSS). Chestnut Hill, MA: Center for the Study of Testing, Evaluation and Educational Policy, Boston College. 
Mullis, I. V. S., Martin, M. O., \& Foy, P. (2008). TIMSS 2007 international mathematics report: Findings from IEA's trends in international mathematics and science study at the fourth and eighth grades. Chestnut Hill, MA: TIMSS \& PIRLS International Study Center, Boston College.

National Council of Teachers of Mathematics. (2000). Principles and standards for school mathematics. Reston, VA: Author.

Nicolaidou, M., \& Philippou, G. N. (2003). Attitudes towards mathematics, self-efficacy and achievement in problem solving. In M. A. Mariotti (Ed.), European Research in Mathematics III (pp. 1-11). Pisa, Italy: University of Pisa.

Nicolaou, A. A., \& Philippou, G. N. (2007). Efficacy beliefs, problem posing, and mathematics achievement. In D. Pitta-Pantazi, \& G. Philippou (Eds.), Proceedings of the V Congress of the European Society for Research in Mathematics Education (pp. 308-317). Larnaca, Cyprus: Department of Education, University of Cyprus.

Nunnally, J. C., \& Bernstein, I. H. (1994). Psychometric theory (3rd ed.). New York, NY: McGraw-Hill.

Pajares, F., \& Kranzler, J. (1995). Role of self-efficacy beliefs and general mental ability in mathematical problem solving. Contemporary Educational Psychology, 20(4), 426-443. doi: 10.1006/ceps.1995.1029

Rao, N., Moely, B., \& Sachs, J. (2000). Motivational beliefs, study strategies and mathematics attainment in high-and low-achieving Chinese secondary school students. Contemporary Educational Psychology, 25(3), 287-316. doi: 10.1006/ceps.1999.1003

Silver, E. A. (1994). On mathematical problem posing. For the Learning of Mathematics, 14(1), 19-28.

Silver, E. A., \& Cai, J. (1996). An analysis of arithmetic problem posing by middle school students. Journal for Research in Mathematics Education, 27(5), 521-539.

Silver, E. A., Mamona-Downs, J., Leung S. S., \& Kenney, P. A. (1996). Posing mathematical problems: An exploratory study. Journal for Research in Mathematics Education, 27(3), 293-309.

Verschaffel, L., \& De Corte, E. (1996). Number and arithmetic. In A. J. Bishop, K. Clements, C. Keitel, J. Kilpatrick, \& C. Laborde (Eds.), International handbook of mathematics education. Part I (pp. 99-138). Dordrecht, Netherlands: Kluwer.

Verschaffel, L., Van Dooren, W., Chen, L. M., \& Stessens, K. (2009). The relationship between posing and solving division-with-remainder problems among Flemish upper elementary school children. In L. Verschaffel, B. Greer, W. Van Dooren, \& S. Mukhopadhyay (Eds.), Words and worlds. Modelling verbal descriptions of situations (pp. 143-160). Rotterdam, The Netherlands: Sense Publishers.

Zhang, D., \& Dai, Z. (2004, July). The "Two basics": Mathematics teaching approach and open-ended problem-solving in China. Regular lecture in the 10th International Congress on Mathematics Education, Copenhagen, Denmark. 